\title{
The significance of microstructure heterogeneities on the fatigue thresholds of aluminum castings
}

\author{
Sascha Gerbe ${ }^{1, *}$, Stephan Knorre ${ }^{1}$, Ulrich Krupp ${ }^{1}$, and Wilhelm Michels ${ }^{1}$ \\ ${ }^{1}$ Institute of Materials Design and Structural Integrity, University of Applied Sciences Osnabrück, 49076 Osnabrück, Germany
}

\begin{abstract}
Industrial in-series aluminum castings contain a wide range of microstructural heterogeneities like differences in secondary dendrite arm spacing (SDAS), eutectic silicon and intermetallic precipitates of varying morphologies and diverse-shaped and -sized porosity. Regarding to technical and economic limitations, the complete elimination of them is hard to achieve, which requires conservative design, i.e., increased wall thicknesses to accommodate the failure tolerance. To improve the performance of cast aluminum products concerning safety and fatigue properties, the present work deals with the significance of such structures with respect to the threshold for crack propagation $\Delta K_{l, t h}$ under pure bending and the fatigue behaviour in the high- and very-high-cycle-fatigue regime (HCF and VHCF). Therefore, two automotive cast alloys taken from engine blocks (AISi8Cu3) and cylinder heads (AISi7Cu0.5Mg) and a gravity die cast set (AISi7Mg0.3), either T6 conditioned or additionally hot isostatic pressed (HIP), were used. For in-series castings, two positions of maximal difference in cooling rate and respective microstructure were extracted. With this set of specimens, the significance of SDAS in interaction with (i) eutectic silicon regions, (ii) intermetallic precipitates in varying occurrence, (iii) the crystallographic orientation, and (iv) the porosity in correlation with the fatigue threshold is shown and compared with first results of fatigue damaging mechanisms in quasi pore-free material.
\end{abstract}

\section{Introduction}

Cast aluminum alloys are frequently used materials in the automotive sector if a good strength to weight ratio is required. Especially, if lightweight solutions at large quantities are demanded in highly-stressed parts (i.e., in automobile drive trains) such alloys representing a good choice. Alloyed with silicon, aluminum provides excellent casting conditions due to better filling properties and a reduced shrinkage behaviour. When considering the extreme complex casting geometries of, e.g., the highly-loaded drive train, engine blocks or cylinder heads, with wide ranges in wall thickness, defect-free castings are technically hard to realize and hence, a compensation by respective conservative design guidelines is required. Since these design guidelines are correlated with high safety factors the full potential of aluminum for lightweight and downsizing concepts cannot be used. Furthermore, complex geometrical circumstances are leading to a strong variation in the local cooling rate of cast products, which acts as a major driving force in determining the value of the secondary dendrite arm spacing (SDAS), the shape and size of the eutectic silicon particles as well as the occurrence of intermetallic precipitates and porosity. In previous studies it was shown that fatigue properties are strongly influenced by heterogeneity in SDAS [1-4], morphology of eutectic silicon [5-6] and porosity [7-10]. The mentioned complexity of typical industrial castings related to respective differences in local cooling rates leads to a more or less wide-ranged appearance of such heterogeneities in microstructure [11]. Furthermore, interactions between some of these characteristics exist, since for example the porosity is influenced by the presence of plate-shaped intermetallic precipitates (i.e., $\alpha$ - and $\beta$-AlFeSi) as they are able to hinder the solidification front [11]. The occurrence of porosity also leads to a strong scattering in results of fatigue investigations [9] according to their random distribution and potential of crack initiation. In a further work by [12] it was shown for quasi pore-free specimens of AlSi7Mg0.3, realized by hot isostatic pressing procedure (HIP) after casting, that crack initiation takes place in the a solid solution, when porosity is absent. This was realized by in-situ high-resolution thermography observation of a specimen equipped with a shallownotch during fatigue tests.

Takin into account the current knowledge about the occurrence of microstructural heterogeneities, like pores, various shaped and sized intermetallic precipitates, or eutectic silicon particles and different heights in the SDAS in in-series cast products, the mechanism-based understanding of the correlation between the coolingrate-dependent microstructure heterogeneities and the fatigue behaviour of cast aluminum alloys are of an essential meaning. Thus, the aim of the present work is

"Corresponding author: sascha.gerbe@hs-osnabrueck.de 
to describe the different influences of typical microstructure heterogeneities on fatigue damaging mechanisms in cast aluminum alloys, with focus on the threshold stress intensity range for technical crack propagation, microstructure-controlled crack propagation and crack initiation. Specimens were extracted from industrial in-series castings of engine blocks (A1Si8Cu3) and cylinder heads (AlSi7Cu0.5Mg); and by means of laboratory gravity-die-cast specimens (AlSi7Mg0.3). Cyclic loading tests were performed under pure bending to observe crack propagation and under uniaxial loading in the high-cycle-fatigue (HCF, up to 107 cycles) and in the very-high-cycle-fatigue (VHCF, from $10^{7}$ cycles up to $10^{9}$ cycles) regime. The long-term objective is to use the resulting findings to develop and to adapt a computer-based procedure to create synthetic microstructures of cast aluminum alloys, which serves as input data to extend an existing and well described short crack model (cf. [13-14]). This model is based on the boundary element model, which follows the approach of microstructural barrier effects on fatigue crack propagation as described by Navarro and de los Rios [15].

\section{Experimental}

Experiments in this work were performed using three conventional hypoeutectic cast aluminum alloys. For two of them, specimens were extracted from in-series castings of engine blocks (secondary metallurgy alloy AlSi8Cu3) and cylinder heads (primary metallurgy alloy AlSi7Cu0.5Mg), both T6 heat treated. For the engine block as well as for the cylinder head the alloy extraction position were chosen with respect to a maximum difference in cooling rates and the related variation in SDAS values. Furthermore, another set of specimens of the primary metallurgy alloy $\mathrm{AlSi} 7 \mathrm{Mg} 0.3$ was laboratory-produced by means of gravity die casting. For some of the experiments, additional hot isostatic pressed (HIP) specimens were studied to eliminate and to work out the influence of porosity on the fatigue properties. Details of specimen extraction and production can be found in Fig. 1; important microstructure properties are summarized in Table 1.

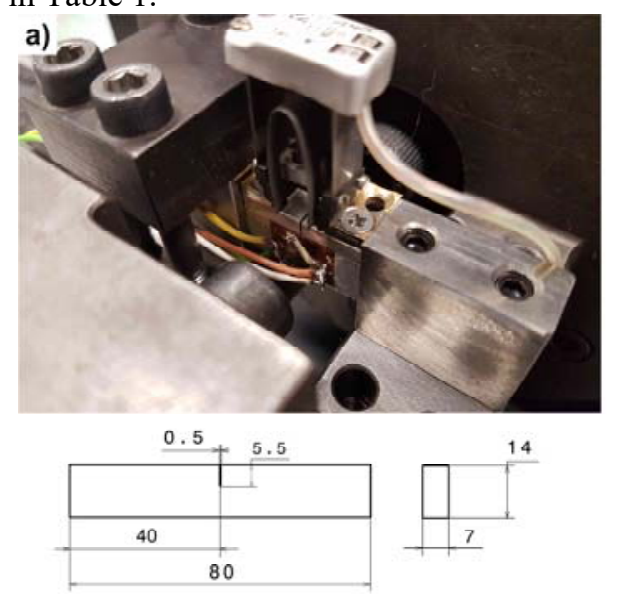

The crack propagation and $\Delta K_{I}$ threshold tests were carried out under pure bending using a resonance testing machine Rumul Cracktronic $(f=100 \mathrm{~Hz})$. For the uniaxial cyclic loading experiments in the HCF and $\mathrm{VHCF}$ regime an ultrasonic resonance testing machine from BOKU Vienna $(f=20 \mathrm{kHz})$ was used. Close-ups of the experimental setups linked to the used specimen geometries are shown in Fig. 2.

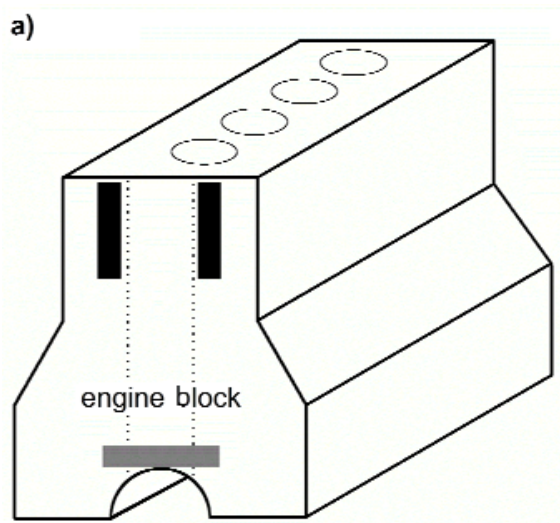

b)
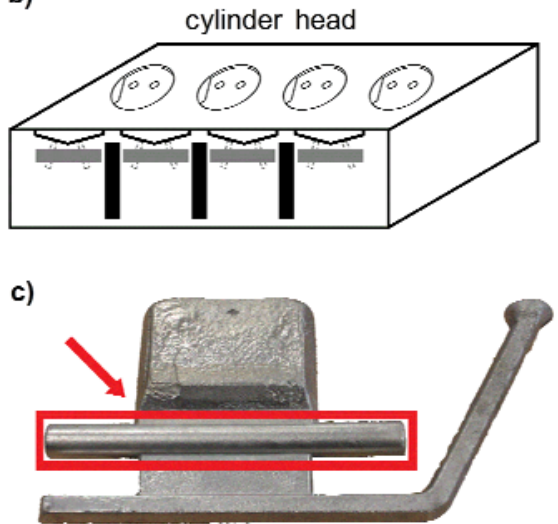

Fig. 1. Specimens were extracted from a) engine blocks (AlSi8Cu3) at stud bolt (black) and bearing seat position (grey); b) cylinder heads (AlSi7Cu0.5Mg) at stud bolt (black) and combustion chamber position (grey); and c) gravity die casting (AlSi7Mg0.3) with specimen extraction position (framed).

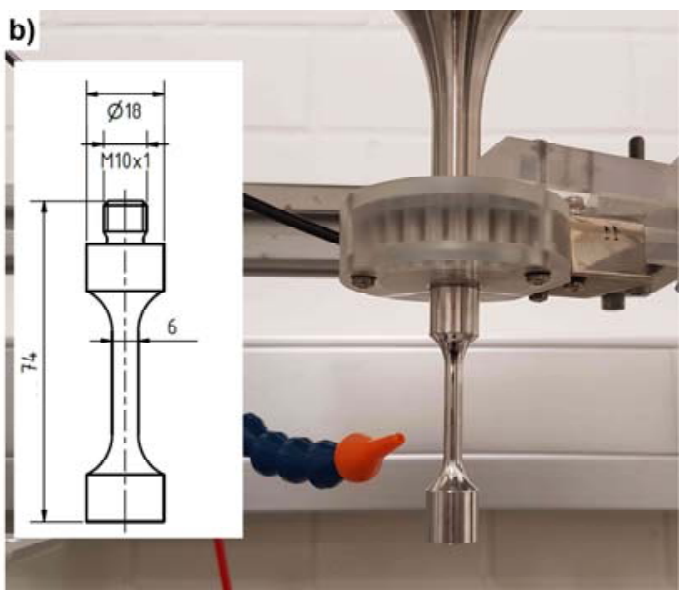

Fig. 2. Close-up of the experimental setups and the respective specimen geometries; a) SENB specimen in the resonance bending system Cracktronic with applied crack/ opening gages; b) uniaxial fatigue testing in the ultrasonic resonance testing machine. 
Table 1. Extraction/ treatment details for the investigated alloys linked to important microstructure characteristics.

\begin{tabular}{|c|c|c|c|c|}
\hline \multirow{2}{*}{ alloy } & position/ state & $\begin{array}{c}\text { SDAS } \\
{[\boldsymbol{\mu \mathbf { m } ]}]}\end{array}$ & $\begin{array}{c}\text { porosity fraction } \\
{[\mathbf{\%}]}\end{array}$ & $\begin{array}{c}\text { av. pore diameter } \boldsymbol{d}_{\boldsymbol{p}} \\
{[\boldsymbol{\mu \mathbf { m } ]}]}\end{array}$ \\
\hline \multirow{2}{*}{$\begin{array}{c}\text { AlSi8Cu3 } \\
\text { engine block }\end{array}$} & stud bolt & 65 & 1.81 & 47.7 \\
\cline { 2 - 5 } & bearing seat & 18 & 0.12 & 9.3 \\
\hline $\begin{array}{c}\text { AlSi7Cu0.5Mg } \\
\text { cylinder head }\end{array}$ & stud bolt & 26 & 0.17 & 8.5 \\
\cline { 2 - 5 } & combustion chamber & 20 & 0.11 & 5.5 \\
\hline $\begin{array}{c}\text { AlSi7Mg0.3 } \\
\text { gravity die cast }\end{array}$ & cast condition & 45 & 1.96 & - \\
\cline { 2 - 5 }
\end{tabular}

The measurement of the crack length during the crackpropagation test was realized by means of crack gages. These gages operate on the principle of alternatingcurrent-potential-drop and were attached to the surface of the SENB specimen directly below the notch (maximal measurable crack length $a_{\max }=5 \mathrm{~mm}$ ). To determine the threshold for technical crack propagation of the stress intensity factor range (SIF) $\Delta K_{I, t h}$ the tests were performed in the load shedding procedure under a

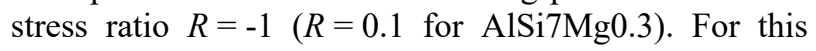
purpose, an initial crack with a length of $a_{\text {pre }}=1.3 \mathrm{~mm}$ is applied to the SENB specimen by a stepwise reduction of the bending moment. After this pretreatment, with the objective to guarantee a small plastic zone at the crack tip, the threshold tests were started immediately with $10 \%$ load increase in relation to the last precrack step. The operating SIF range $\Delta K_{I}$ during the crackpropagation tests is calculated according to Equation 1 with the bending stress range $\Delta \sigma_{b}$, the total crack length $a_{\text {tot }}$ and the geometry factor $Y\left(a_{t o t}\right)$ for SENB specimens (cf. [16]). Further crack-propagation tests were performed to obtain the constant $C$ and the exponent $m$ of the Paris-Erdogan law (Equation 2) [17-18], which states the correlation between the crack-propagation rate $d a / d N$ and the SIF range $\Delta K_{I}$ as shown in Equation 2.

$$
\begin{gathered}
\Delta K_{I}=\Delta \sigma_{b} \cdot \sqrt{\pi \cdot a_{t o t}} \cdot Y\left(a_{t o t}\right) \\
\frac{d a}{d N}(\Delta K)=C \cdot \Delta K^{m}
\end{gathered}
$$

Following the specification of ASTM E 647 [19] the threshold $\Delta K_{I, t h}$ is reached if a minimum of five measurement points with a sufficient linearity were detected for $10^{-10} \mathrm{~m} /$ cycle $<d a / d N<10^{-9} \mathrm{~m} /$ cycle. The resulting linear formula has to be extrapolated to $d a / d N=10^{-10}$ and thus returns the respective threshold value for the SIF range $\Delta K_{I, t h}$. In case of the examination of the Paris law, experiments were carried out with constant bending moment $(R=-1$ for in-series casting specimens; $R=0.1$ for laboratory $\mathrm{A} 1 \mathrm{Si} 7 \mathrm{Mg} 0.3)$. Due to the propagating crack, the geometry factor $Y\left(a_{t o t}\right)$ and according to this the SIF range $\Delta K_{I}$ rises until $a_{t o t}=a_{\max }$. Selected SENB specimens were analyzed post-testing by means of light microscopy and high-resolution scanning electron microscopy (SEM), Zeiss Auriga FEG, equipped with an electron-back-scatter-diffraction detector (EBSD), which allows to correlate the crack growth to crystallographic orientations of the grains.

All uniaxial cyclic loading tests in this work were performed with a stress ratio of $R=-1$ and limited by the defined abort criterions of a maximum decrease in resonance frequency $(\Delta f=-2 \%$, fail $)$ or a maximum number of cycles $\left(N=10^{9}\right.$ cycles, run-out). To avoid specimen heating during the high-frequency fatigue test, a pulse-pause mode was applied $(200 \mathrm{~ms}$ loaded state followed by $800 \mathrm{~ms}$ unloaded state). Additionally, an air cooling system was attached. To obtain statistically confirmed values for the fatigue limit $\sigma_{f}$, the test series were performed following the step method by Hück [20], accounting for a fatigue limit criterion of $N=10^{7}$ cycles.

\section{Results and Discussion}

\subsection{Crack-propagation experiments}

During the crack-propagation tests under pure bending, different microstructural heterogeneities were observed as being of high influence on the threshold value $\Delta K_{I, t h}$. The significance of the SDAS value is shown for the specimens extracted from engine blocks. The difference in SDAS is the highest in comparison between the stud bolt (low cooling rate) and the bearing seat (high cooling rate). Significantly lower values for the threshold $\Delta K_{I, t h}$ were obtained for the high cooling rate (low value of SDAS) as shown in Fig. 3a. Also, the crystallographic orientation in interaction with the morphology and size of the eutectic was found to have an appreciable influence on the crack-propagation rate for low SIF ranges near the threshold $\Delta K_{I, t h}$ (cf. Fig. 3b) in the test series of the cylinder head. Another strong effect is provoked by the occurrence of porosity as it is obvious form the crack-propagation rate vs. SIF range plot in Fig. 3c. In this example, a laboratory AlSi7Mg0.3 specimen was tested in the as-cast T6 heat-treated condition and compared to an analogues produced but additionally HIP treated specimen to determine the influence of porosity. Due to the high fraction of pores in the material, locally increased SIF ranges are leading to substantially lower global threshold values $K_{I, t h}$. 

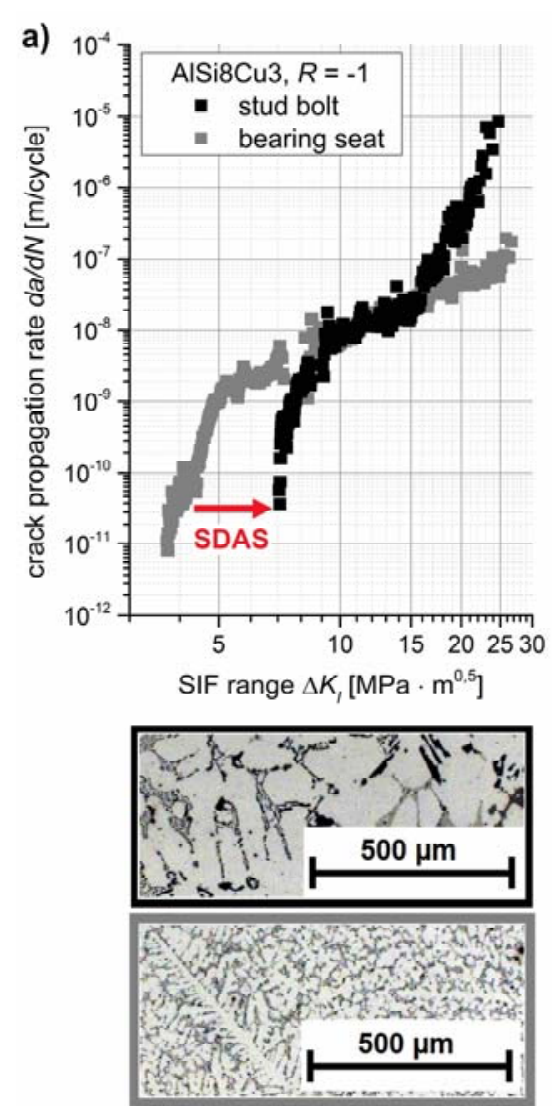
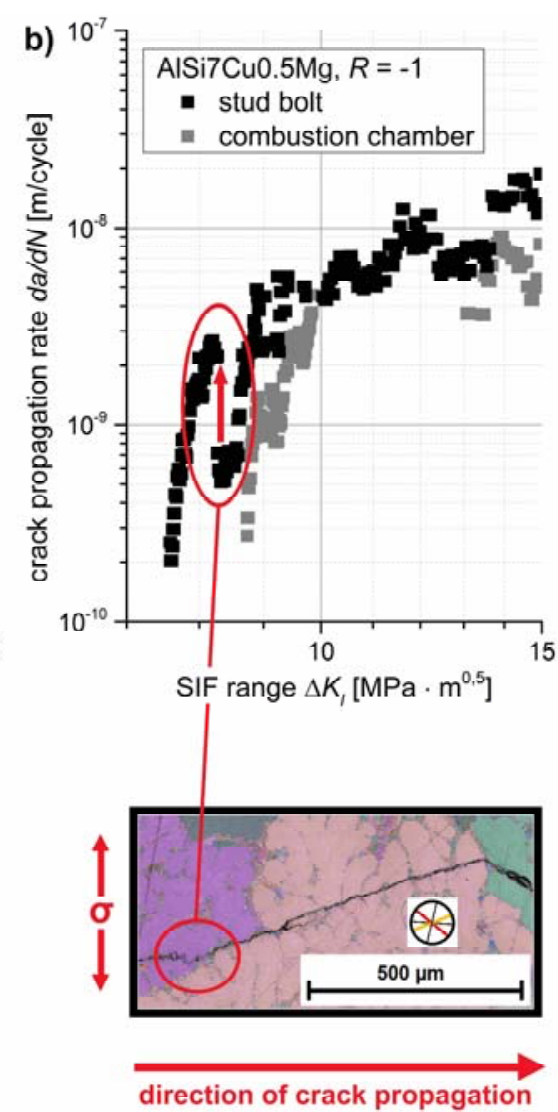
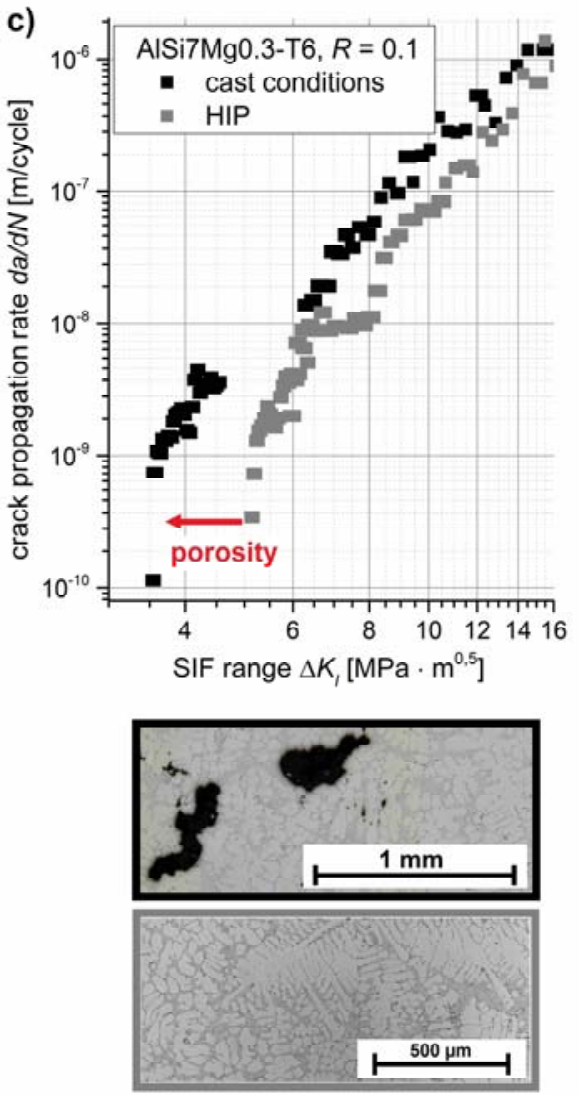

Fig. 3. The threshold value for technical crack propagation $\Delta K_{I, t h}$ is influenced by different microstructure heterogeneities as shown via crack propagation graphs and light microscopy/ EBSD scans for a) the cooling-rate-dependent SDAS value represented by micrographs of stud bolt (black frame) and bearing seat microstructure (grey frame); b) the crystallographic orientation regarding to the direction of principal stress with highlighted position of entering the next grain via (111) slip plane (circled); c) the occurrence of shrinkage or gas porosity in $\mathrm{AlSi} 7 \mathrm{Mg} 0.3-\mathrm{T} 6$ specimens in conditions as cast with $\mathrm{T} 6$ treatment (black frame) and additionally HIP treated (grey frame).

Since the occurrence of interdendritic eutectic silicon is directly related to the SDAS value and acting as a barrier against crack growth, the SDAS is a most significant parameter in increasing fatigue resistance. However, a reduction in SDAS leads to lower threshold values because of the linear characteristic of the eutectic regions between two secondary dendrite arms. If a crack for example propagates shear-stress controlled on a (111) slip plane (cf. Fig. 3b, EBSD scan) such line-like barriers are showing just a small reduction in crack propagation rate. In a coarser microstructure (cf. Fig. 3a, stud bolt, framed black), the eutectic regions are present in a bimodal distribution. Between the secondary dendrite arms they occur in analogy to microstructures with lower SDAS but in bigger and rather round-shaped cells accompanied by more plate-shaped silicon particles inside the grains as well as on grain boundaries. If the crack path enters such a eutectic cell loaded with low SIF ranges, the crack-tip will be deflected multiple times and propagation takes place at the phase boundary of $\alpha$ solid solution and eutectic silicon as shown in Fig. 4. This leads to an effective drop in the crack propagation rate $\left(d a / d N\right.$ decreases from $10^{-9} \mathrm{~m} /$ cycle to $3 \cdot 10^{-}$ ${ }^{11} \mathrm{~m} /$ cycle) giving rise to the higher threshold value of the material extracted from engine blocks stud bolt (cf. Fig. 3a). Also the crack path was deflected along with a reduction in crack propagation rate $d a / d N$ by intermetallic precipitates of species $\mathrm{Al}_{2} \mathrm{Cu}$ or $\alpha$ - and $\beta$ AlFeSi.

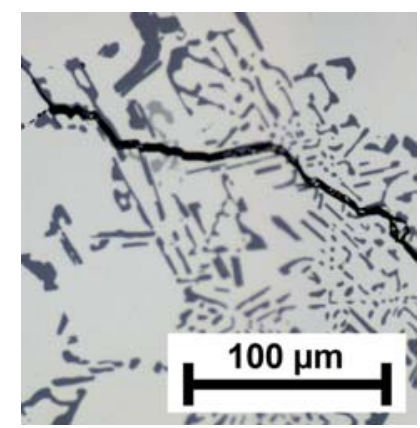

Fig. 4. Crack propagation rate drops due to passing a eutectic cell under low SIF range. At this point, the crack-propagation test was stopped, followed by further investigations regarding to observe the Paris-law behaviour.

The crystallographic orientation of the grains is another important influence factor to the threshold value $\Delta K_{I, t h}$. As shown in Fig. $3 \mathrm{~b}$, the crack propagation rate was already low enough to stop the experiment (according to [19]; cf. Fig. $3 \mathrm{~b}$ for $\Delta K_{I} \approx 8.5 \mathrm{MPa} \cdot \mathrm{m}^{0.5}$ ). However, $d a / d N$ suddenly increases by a factor of 6 . As determined by post-testing EBSD analysis, this can be attributed to 
the crack tip penetrating the next grain along a highly loaded (111) slip plane (Schmid factor $M_{S}=0.46$ ). Otherwise, the crack propagation curves for both extraction positions of the cylinder heads (stud bolt and combustion chamber) would be almost identically. This would be expectable due to the low variation in microstructural characteristics (cf. Table 1).

Furthermore the significance of porosity to the threshold regime is shown in Fig. 3c. The occurrence of pores leads to multiple regions with an increased SIF range during cyclic loadings. Due to this, the crack path is influenced by pores since the direction of crack growth is attracted by these local heterogeneities of the stress intensity field. Such a behaviour of a crack in the near of a pore is shown exemplarily for a specimen from engine blocks stud bolt in Fig. 5.

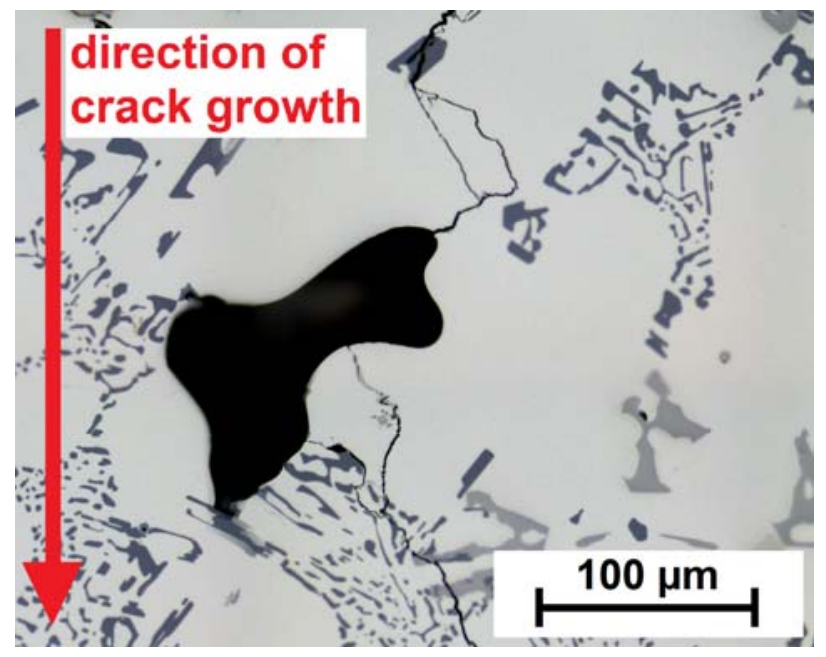

Fig. 5. Crack path through a SENB specimen of AlSi8Cu3 (engine block, stud bolt) influenced by the presence of a pore.

To determine the local influence of events like this during crack-propagation test a closer look to the $d a / d N$ measurements was made. In the experiments regarding to the results in Fig. 3c the crack propagation rate is calculated with respect to an incremental crack growth of $\Delta a_{i n c}=0.1 \mathrm{~mm}$. In this procedure the necessary number of cycles will be count and divides the incremental grown distance to generate the average crack propagation rate $d a / d N$ which overlaps such small microstructural influences. The closer examination of $d a / d N$ regarding to a smaller increment of $\Delta a_{i n c}=10 \mu \mathrm{m}$ enables to detect high accelerations if the crack passes pores. This local effect in multiple occurrence leads to a global effect that results in the shown reduction of the threshold value $\Delta K_{I, t h}$ (cf. Fig. 3c)

\subsection{Fatigue experiments}

\subsubsection{Tests on porosity-containing material}

During uniaxial cyclic loading tests carried out using the ultrasonic resonance testing machine, porosity was identified as major crack-initiating defect. In the case of the material with the more coarse microstructure
(AlSi8Cu3, engine block, stud bolt, low cooling rate) having a higher fraction of lager porosity, the crack starts at surface pores. Compared to this, crack initiation for the material with lower SDAS value (AlSi8Cu3, engine block, bearing seat) was found at surface-near pore accumulations. Exemplarily, both cases are shown in Fig. 6. Nevertheless, the fatigue limit $\sigma_{f}$ (criterion $N=10^{7}$ cycles) is significantly higher for the specimens with lower SDAS. Results of the fatigue tests linked to them from crack-propagation for this alloy set can be found in Table 2.
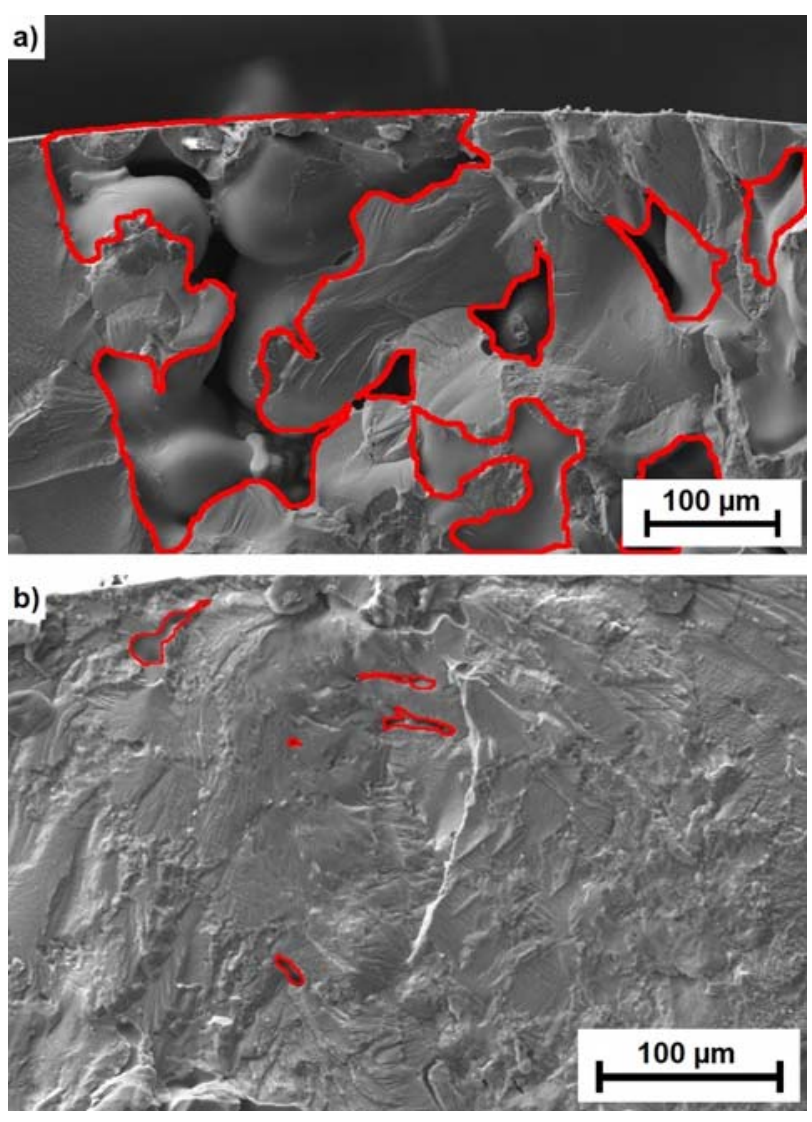

Fig. 6. Micrographs of fracture surfaces from fatigue tests for engine block specimens from a) stud bolt and b) bearing seat with different crack provoking porosities.

Table 2. Summarized results of fatigue and crack-propagation tests for the cast aluminum alloy $\mathrm{AlSi} 8 \mathrm{Cu} 3$.

\begin{tabular}{|c|c|c|}
\hline $\begin{array}{c}\text { engine block } \\
\text { position }\end{array}$ & $\begin{array}{c}\text { fatigue limit } \boldsymbol{\sigma}_{\boldsymbol{f}} \\
{[\mathrm{MPa}]}\end{array}$ & $\begin{array}{c}\text { threshold } \Delta \boldsymbol{K}_{\boldsymbol{I} \text {,th }} \\
{\left[\mathbf{M P a} \cdot \mathbf{m}^{\mathbf{0 . 5}}\right]}\end{array}$ \\
\hline stud bolt & $68 \pm 1$ & 7.0 \\
\hline bearing seat & $114 \pm 23$ & 4.4 \\
\hline
\end{tabular}

Using the results given in Table 2, a threshold diagram according to Kitagawa and Takahashi [21] including the modification by El Haddad [22] can be established using Equation 3 and 4. The Kitagawa-Takahashi diagram represents the correlation between a present defect with the size $a$ (e.g. a critical shaped intermetallic precipitate or the projected diameter of a pore) and the sustainable cyclic stress amplitude $\Delta \sigma_{t h}$ which is limited by the 
fatigue limit $\sigma_{f}$ until the threshold crack length $a_{0}$ is exceeded. For higher defect sizes, the threshold $\Delta \sigma_{t h}$ decreases (cf. Equation 3).

$$
\begin{gathered}
\Delta \sigma_{t h}=\frac{\Delta K_{I, t h}}{\sqrt{\pi \cdot\left(a+a_{0}\right)}} \\
a_{0}=\frac{1}{\pi} \cdot\left(\frac{\Delta K_{I, t h}}{\Delta \sigma_{f}}\right)^{2}
\end{gathered}
$$

The resulting Kitagawa-Takahashi diagrams for both microstructure conditions from engine block are shown in Fig. 7, where the influence of SDAS on the progression of the threshold value $\Delta \sigma_{t h}$ is highlighted by arrows.

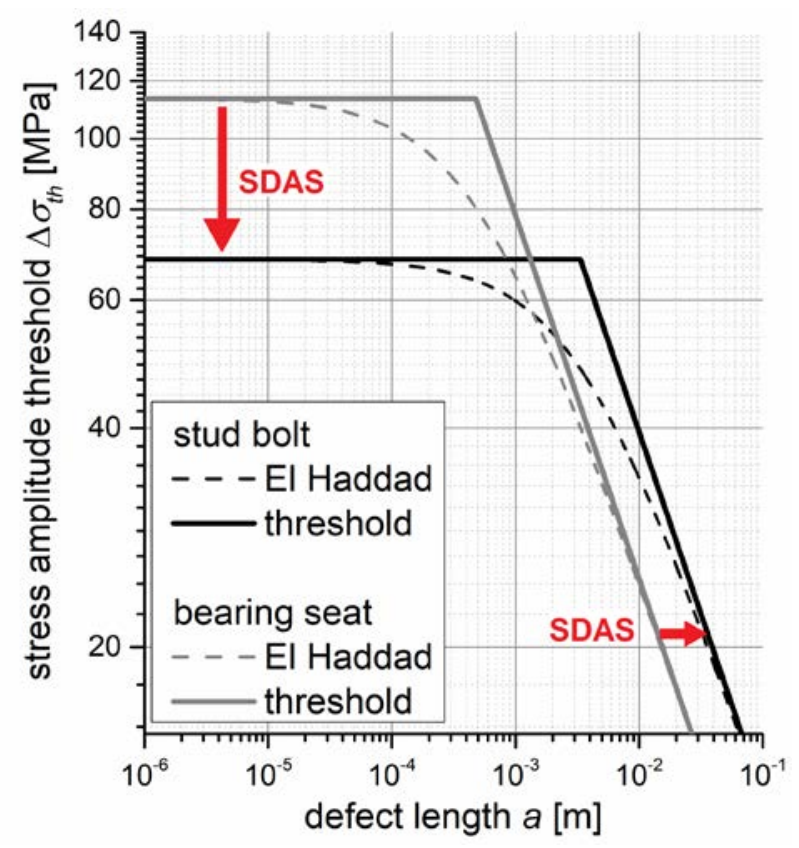

Fig. 7. Kitagawa-Takahashi diagrams for the varying microstructure characteristics in $\mathrm{AlSi} 8 \mathrm{Cu} 3$ (engine block) resulting from different cooling-rate-dependent SDAS values. The arrows represent the gradient of SDAS values.

As it is shown above, the SDAS value has a significant influence on the fatigue and crack-propagation properties. The Kitagawa-Takahashi diagram indicates the better resistance against fatigue for lower SDAS values in the first horizontal part of the graph but at the same time the reduced defect tolerance (shift of the decreasing part of the graph to lower defect lengths $a$ ).

\subsubsection{Tests on quasi pore-free material (HIP treated)}

If the major crack initiating defect in form of pores is eliminated, a closer examination of the early VHCF damage mechanisms in correlation with intrinsic metallurgical parameters is possible. Former results on this aspect were shown for the alloy AlSi7Mg0.3 and published in [12]. By means of high-resolution thermography, crack initiation was found to take place within the dendritic $\alpha$ solid solution. Via the formation of a well visible hotspot, the initiation process was detectable at approximately $40 \%$ of the number of cycles to failure (here $N_{f} \approx 3.8 \cdot 10^{8}$ cycles). Additionally, first experiments on HIP treated cylinder head specimens (AlSi7Cu0.5Mg) were performed on stress amplitudes $\sigma$ where for non-HIP treated specimens failures in the region of $N_{f} \approx 10^{8}$ cycles occur. On this stress level after $N=8 \cdot 10^{9}$ cycles (run out) no crack was detected for the quasi pore-free cylinder head (combustion chamber) set. The post-testing observation carried out using the SEM showed some traces of microstructural fatigue damage (slip markings) distributed over the complete surface of the specimen's gage length (cf. Fig. 2a). Results of the SEM investigation are shown in Fig. 8.
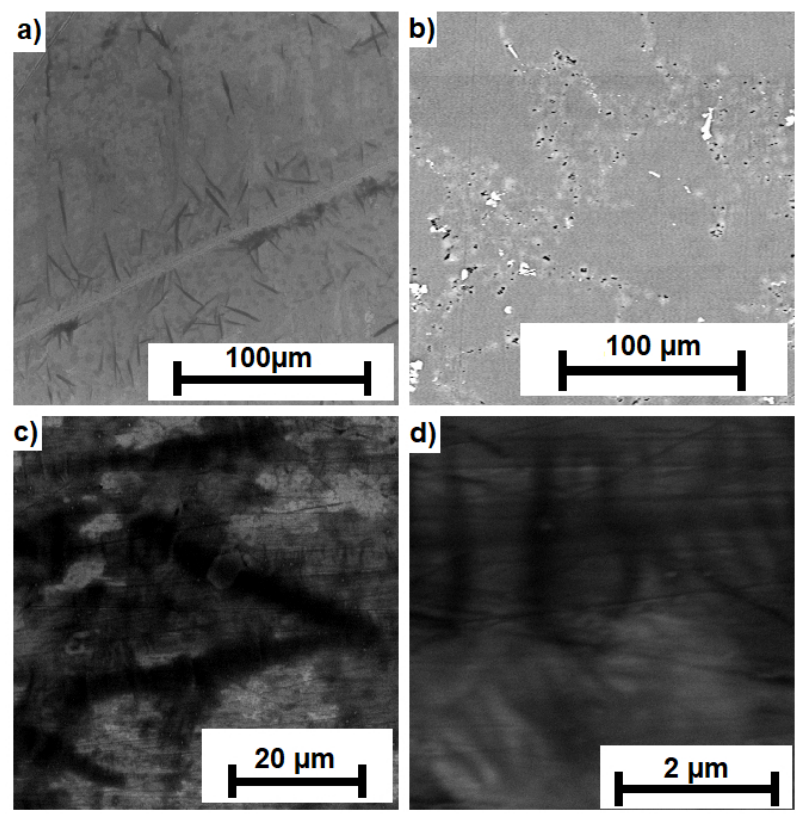

Fig. 8. Two kinds of defects on the surface of a HIP-treated cylinder head combustion chamber specimen after $N=8 \cdot 10^{9}$ cycles; a) in-lens electron image of slip markings in the vicinity of a polishing scratch; b) defects on the eutectic silicon particles in back scatter contrast (dark spots in the brighter region); c) and d) higher magnifications of the slip markings from a).

According to Fig. 8a, the damage is located within the $\alpha$ solid solution represented by local plastic deformation. Due to this deformation, EBSD measurements did not lead to useful results and hence, a correlation of the slip markings to the potential traces of the slip traces was not possible yet. Furthermore, it was shown that the eutectic silicon particles at the surface revealed debonding from the surrounding $\alpha$ solid solution (cf. Fig. 8b). This supports the assumption that at stress levels close to the fatigue limit the crack initiation mechanism takes place in both, the interdendritic eutectic and the dendrites. However, this represents the present state of preliminary experimental work on the HIP treated specimens, where further investigations are in progress. 


\section{Conclusions}

By means of crack propagation and fatigue experiments on different cast aluminum alloys with varying microstructure conditions, the significance of heterogeneities like SDAS, intermetallic precipitates, eutectic regions and porosity was quantified. Lower SDAS, fine and only line-shaped eutectic regions between secondary dendrite arms and a higher amount of porosity fraction lead to lower threshold values $\Delta K_{I, t h}$ for technical fatigue crack propagation. Furthermore, the crystallographic orientation of the grains affects the resistance against crack growth at near-threshold SIF ranges due to preferred propagation on (111) slip planes. If in such a case the material contains a low SDAS value and accordingly fine defined eutectic regions, the barrier effect is decreased dramatically. Near crack tip porosity influences the crack path by a locally increased stress intensity field, which is able to force the crack to propagate directly through them. Furthermore, crack initiation for porosity-containing material was shown to occur either at large surface pores (high fraction of porosity) or at pore accumulations (low fraction of porosity). If porosity is eliminated due to a HIP treatment, the fatigue limit will be increased significantly.

It is the objective of current work to systematically expand the range of microstructure properties (with regard to cooling rate and the respective SDAS values) to obtain a more detailed and quantitative definition of microstructural barriers to fatigue crack propagation. The results will serve to define reference microstructures of cast aluminum alloys to be implemented in a short crack modelling environment. For this purpose, wedgeshaped castings have been produced. Due to their stepwise decreasing thickness, a systematic variation in cooling rate and SDAS is possible.

The authors acknowledge the financial and technical support by the German Federal Ministry of Education and Research (BMBF), Germany, by Nemak Dillingen GmbH, RWP GmbH and deutsche Forschungsgemeinschaft (grant DFG KR1999/19).

\section{References}

1. R. Gonzáles et al., Int. J. Fatigue 54, 118-126 (2013)

2. D.A. Lados, D. Apelian, Mater. Sci. Eng. A 385, 200-211 (2004)

3. B. Zhang, D.R. Poirier, W. Chen, Metall. Mater. Trans. A 30, 2659-2666 (1999)

4. M.I. Houria, Y. Nadot, R. Fathallah, M. Roy, D.M. Maijer, Int. J. Fatigue 80, 90-102 (2015)

5. K. Gall, N. Yang, M. Horstemeyer, D.L. McDowell, J.H. Fan, Metall. Mater. Trans. A 30, 3079-3088 (1999)

6. S. Siegfanz, A. Giertler, W. Michels, U. Krupp, Mater. Sci. Eng. A 565, 21-26 (2013)

7. D.L. McDowell, K. Gall, M.F. Horstemeyer, J. Fan, Eng. Fract. Mech. 70, 49-80 (2003)
8. L. Ceschini, A. Morri, G. Sambogna, J. Mater. Process. Technol. 204, 231-238 (2008)

9. J.Z. Yi, Y.X. Gao, P.D. Lee, H.M. Flower, T.C. Lindley, Metall. Mater. Trans. A 34, 1879-1890 (2003)

10. A. Ben Ahmed, A. Nasr, A. Bahloul, R. Fathallah, Int. J. Adv. Manuf. Technol. 92, 1113-1125 (2017)

11. L. Lu, A.K. Dahle, Metall. Mater. Trans. A 36, 819835 (2005)

12. S. Knorre, J. Tenkamp, U. Krupp, W. Michels, F. Walther, $7^{\text {th }}$ International Conference on Very High Cycle Fatigue, 222-227 (DVM, Dresden, 2017)

13. B. Künkler, Mechanismenorientierte Lebensdauervorhersage unter Berücksichtigung der Mikrostruktur, Diss. (VDI-Verlag, Siegen, 2006)

14. U. Krupp, Fatigue Crack Propagation in Metals and Alloys (Wiley VCH, Weinsheim, 2007)

15. A. Navarro, E.R. de los Rios, Philos. Mag. A 57, 1536 (1988)

16. D. Gross, T. Seelig, Bruchmechanik, $5^{\text {th }}$ ed. (Springer, Berlin, 2011)

17. P.C. Paris, M.P. Gomez, W.E.A. Anderson, Trends Eng. 13, 9-14 (1961)

18. P.C. Paris, F.A. Erdogan, J. Basic Eng. 85, 528-534 (1963)

19. ASTM E 647, Standard Test Method for Measurement of Fatigue Crack Growth Rates (ASTM Inter-national, West Conshohocken, 2000)

20. M. Hück, Matterwiss. Werksttech. 14, 15-36 (1983)

21. H. Kitagawa, S. Takahashi, ASM Proceedings of $2^{\text {nd }}$ International Conference on Mechanical Behavior of Materials, 62731 (Metalspark, Ohio, 1976)

22. M.H. El Haddad, T.H. Topper, K.N. Smith, Eng. Fract. Mech. 11, 573-584 (1979) 